\title{
Adapting the Macaulay duration for defaultable AND OPTION-EMBEDDED BONDS
}

\author{
Gary van Vuuren \\ School of Economics, North-West University and Fitch Ratings, London \\ Paul Styger \\ School of Economics, North-West University
}

\begin{abstract}
Most contemporary bonds have embedded options and all face the possibility of default. Both features introduce risk (the former market risk and the latter credit risk) by altering the quantity and timing of the promised cash flows. The Macaulay duration, although a popular risk tool, is increasingly unable to cope in this complex financial environment. While the Macaulay duration has undergone modifications before, a new theoretical framework is now introduced which augments its functionality while retaining its tractability. The approach - though still unable to isolate the effects of the two features - yields consistent results which agree well with empirical data.
\end{abstract}

Abstract

JEL C13, E43, G12

\section{1 \\ Introduction}

For most institutions, loans are the largest and most obvious source of credit risk, ${ }^{1}$ although credit (or counterparty) risk from instruments other than loans (including acceptances, interbank transactions, trade financing, foreign exchange transactions, financial futures, swaps, bonds, equities, options, and in the extension of commitments and guarantees, and the settlement of transactions) also exist. Credit losses arise from lax credit standards for borrowers and counterparties, poor risk management and a lack of attention to changes in economic or other conditions that can lead to deterioration of the counterparty credit standing or rating (BIS, 2001: 23).

Market risk $^{2}$ accounts for a smaller, but still considerable, portion of an institution's financial risk. In turn, a substantial fraction of market risk arises from instruments that are partly or completely interest rate dependant. Unexpected market portfolio losses are due mainly to poor risk measurement and inaccurate pricing. Managing these risks is essential to the long-term success of any financial organisation. Indeed, the overall aim of risk management is to maximise an institution's risk-adjusted rate of return by maintaining credit and market risk exposures within acceptable parameters (Schönbucher, 2003).

Institutions are increasingly realising the need to identify, measure, monitor and control credit and market risks as well as to determine that they hold adequate capital against these risks and that they are adequately compensated for risks incurred. In recognition of these concerns, the Bank for International Settlements (BIS, 2005) introduced new capital adequacy standards in early 2007. The new accord initiates a muchimproved methodology for estimating credit risk while leaving the market risk component almost unchanged from the 1995 amendment to the 1988 Basel Accord ${ }^{3}$.

The Macaulay duration features prominently as a tool for measuring both credit and market risk (e.g. Nawalkha, 1999: 12; Sarkar, 2000: 509 and Jacoby, 2003: 2301), but the standard Macaulay duration formulation - which estimates 
the price sensitivity of loan instruments to changes in interest rates - ignores two important loan features: the possibility of call and the probability of default. This paper explores both of these in the light of a new conceptual framework: Section 2 provides a literature review of recent work conducted in the field of duration analysis with specific emphasis on option-embedded and default features.

Bierwag (1987: 325) advocated the possibility of a dual-duration paradigm for defaultable bonds and a "duration drift" hypothesis for option-embedded bonds, but neither the theoretical nor the empirical implications of his proposals have been explored to date. Bierwag's theoretical approaches are now applied to the problems of bond defaultability (expanded in Section 3) and bonds with embeddedoptionality (examined in Section 4). Empirical results obtained from South African bond data are also analysed in these sections. The ideas and results presented in Sections 3 and 4 owe much to Bierwag's (1987) proposals. Section 5 concludes the paper.

\section{2}

\section{Literature survey}

One of the most popular interest rate risk sensitivity measures - the Macaulay duration - is now in its eighth decade of use and has remained remarkably robust despite its application to an ever more complex set of instruments for which it was never originally intended. The Macaulay duration is, for example, increasingly unable to cope with financial instruments that suffer the possibility of default. As a result, accurate estimation of price changes for instruments with inherent credit risk is severely obstructed. The burgeoning use of interest rate derivatives embedded in fixed income instruments has also eroded its validity as it is unable to deal with instruments that may be put or called some time before maturity of the underlying bond. It also cannot adequately measure the inherent risk in instruments of perpetual maturity (such as deposit accounts). The assumptions required to justify its use have recently come under increased criticism as the stochastic nature of interest rates, credit (default) events and the exercising of optionality have become better understood (see e.g: Fons, 1990; Babbel et al., 1997; Duffie \& Singleton, 1999; Fisher, 2004; Rosenberg, 2004; van Vuuren \& Styger, 2006 and Kraftb \& Munkc, 2006).

The Macaulay duration remains widely-used and there are few signs that this will change. As a risk measure for instruments whose value inherently depends on an underlying yield curve, it enjoys relatively unrivalled success. It is a relatively straightforward concept and is easily implemented and applied to both individual instruments and portfolios of instruments. It has survived virtually unchanged and unchallenged, since its introduction in 1938 (Macaulay, 1938: 27). But it is this very immutability that cemented the Macaulay duration firmly into the interest rate risk management arena that has now begun to threaten its survival (Eom et al., 2002).

The financial world of 1938 is profoundly different to the one ushered in by the new millennium. Tools that were fashionable and reliable in the 1930s must be altered and adapted if they are unable to cope with the highly-evolved, complex contemporary financial environment. Alternatively they should be discarded completely if these modifications do not yield satisfactory results. The Macaulay duration has undergone only minor adaptations to date; the majority of these have been appended to the existing mathematical infrastructure, leaving the original exposition virtually unaltered. Many add-ons (such as those designed to deal with the effects of default and embedded-optionality) have enjoyed varying degrees of success, and almost all have approached these omissions from a contingent claims model point of view.

Fons (1990: 21) presented a theoretical framework for the adjustment of duration for the risk of default and concluded that risk-adjusted duration should be lower than its Macaulay counterpart. His conclusion, however, depends heavily on his assertion that a bond's credit quality is negatively correlated to the level of the riskless term structure. Fons' empirical evidence demonstrates that, during the 1980-1988 period, the risk-adjusted duration of corporate bond indices of all ratings was significantly lower than their Macaulay duration. It is also important to note that Fons ignores embedded-optionality as 
a factor in measuring the bond's price sensitivity to riskless rate changes. Many corporate bonds included in the indices he uses are, in fact, callable and subsequent studies have shown that callability is an even more important adjustment factor for highly rated corporate bonds relative to the adjustment for default risk (e.g. Jacoby, 2003: 142 and Acharya \& Carpenter, 2002: 1371).

Babbel, Merrill, and Panning (BMP) (1997) compared interest sensitivities of risk-prone and risk-less bonds and isolated the effects of default risk. BMP utilised option-pricing technology to calculate risk-adjusted duration and compared it to the duration of matched, synthetic Treasury bonds. They found that risk-adjusted duration was lower than riskless duration for all levels of yield spreads, with the difference monotonically increasing with yield spreads. The statistical robustness of BMP's results, however, has been questioned and it has been pointed out that the implications of their results are less important to bond portfolio managers who use Macaulay duration with the risky yield. This is because the underlying reference to estimate the sensitivity of the value of a risky bond changes in the riskless term structure (Jacoby \& Roberts, 2003: 2306).

Fooladi, Roberts, and Skinner (FRS) (1997: 13) derived a risk-adjusted duration measure for corporate bonds while considering both risk aversion of investors and a delay period in recovery in the default process (a feature introduced in a different form by Bierwag \& Kaufman, 1988: 41). FRS showed that incorporating the delay period, especially for zero-coupon bonds with a material risk of default, may result in a risk-adjusted duration greater than the bond's time to maturity. This result was attributed to the positive probability that the issuer of a zero-coupon bond would default at maturity and bond-holders would receive any recovered amount only after a certain waiting period (delay period). Jacoby (2003: 133) also included risk aversion and delay in recovery, and found a similar result. Jacoby's risk-adjusted duration may also be greater than the bond's maturity. However, it will always be greater than the Fisher-Weil duration (or Macaulay duration) due to the delay period when flat term structures are assumed. Like FRS, Jacoby assumed independence between default probability and the riskless term structure.

Chance (1990: 266) provided the first contingent claims model in an effort to understand the effects of default risk on corporate bond duration. His model was based on fairly restrictive assumptions (namely that the duration of a firm's underlying stock could only be greater than zero since the duration of the firm's assets were assumed to be zero). Merton's (1974: 461) option-pricing model for the valuation of risky pure discount bonds was used as well as results obtained by Garman (1985:310) for the sensitivity of an option's value to changes in interest rates. Chance (1990: 268) expressed the duration of the discount bond as the weighted average of the duration of a riskless discount bond and that of a put option written on the firm's assets. Like Merton, Chance assumed that the firm's assets followed a diffusion process independent of the short riskless rate process and, therefore, the duration of the firm's assets must be zero. Although Chance's model is intuitively appealing, it is difficult to construct in practice because the duration of a firm's assets cannot be directly observed and is thus assumed to be zero. Zero asset duration is also implicitly assumed in the work of Merton (1974: 462) and Galai and Masulis (1976: 122) since they are both based on the Black and Scholes option pricing framework.

Nawalkha (1996: 241) extended Chance's model by allowing dependence between the two processes, implying a nonzero duration of the firm's assets. Unlike Chance's duration, Nawalkha's duration was not restricted to be lower than the maturity of the risky discount bonds. Since the Macaulay duration of a pure discount bond is its time to maturity, Nawalkha's model implied that the risk-adjusted duration of a pure discount corporate bond could be either lower than, equal to, or higher than its Macaulay duration. Nawalkha (1999: 14) provided a contingent claims analysis of the interest rate characteristics of corporate liabilities by using Vasicek's (1977: 182) mean-reverting term structure model in Merton's (1974: 468) option pricing model. He found that the duration of 
defaultable securities, issued by firms having assets with low interest rate-sensitivity, was an increasing function of the bond's default risk. The reverse is true for bonds having assets with a high interest rate-sensitivity. An important consequence of Nawalkha's model is that the duration of a defaultable zero coupon bond will be greater than the corresponding duration measure proposed by Chance.

Acharya and Carpenter (2002:1356) developed a model for the valuation of option-embedded, defaultable bonds. Both interest rates and firm value were considered stochastic and the option and default decisions were endogonised. With respect to interest-rate sensitivity, as in other models applying option-pricing technology, their model implied that default risk alone reduced the bond's duration. Acharya and Carpenter also showed that option risk, when isolated from the risk of default, also shortened bond duration. When considering the combined effect of default and option risks, they demonstrated that as the probability of default increased, the impact of the call on the bond duration diminished. A higher default risk provided an incentive to the issuer to wait longer before calling the bond and resulted in a higher effective bond duration.

Kihn (1994: 36) explored default and optionembedded risks for corporate bonds and paid special attention to cases where both credit quality and interest rates decline. For low grade bonds the credit deterioration depresses bond prices to a level low enough to discourage issuers from exercising the call provision. Kihn provided empirical support for his hypothesis by analysing return volatility of high and low grade bonds. His results supported the theoretical implications of Acharya and Carpenter's (2002: 1366) bond pricing model.

Bierwag et al. (1983: 115); Morgan (1986: 90) and Ott Jr (1986: 928) all extended work on the Macaulay duration measure used for corporate securities, but all ignored the effects of default risk. Bierwag et al. (1988: 41) did further work in which he assumed that a simple linear relationship exists between the risk adjusted return and a defaultable duration. He found that the error in estimating the Macaulay duration by not taking stochastic processes of default into account were larger the greater the default risk premium.
Xie et al. (2002) used the Cox, Ingersol, Ross (1985: 388) term structure model to evaluate duration of defaultable securities. Xie found that the duration for defaultable bonds could be longer or shorter than default-free bonds, depending on the relationship between interest rates and the default intensity of defaultable bonds.

Several approaches have been developed regarding optimal exercise strategies for embedded call options. In particular, one can distinguish between models using partial differential equation (PDE) techniques and the Martingale approach. Regarding the PDE-based literature, models with default were advocated by Merton (1974: 470), who argued that prices of a callable, defaultable bond solve a PDE subject to boundary conditions that describe default and call events. Closed-form solutions do not exist so finite-difference methods are applied. Kim, Ramaswamy, and Sundareasan (1993: 121) extend this work by allowing for stochastic interest rates.

In Sarkar (2000: 511) imperfections in the capital structure (refunding costs, taxes, bankruptcy costs) alter the optimal call policy. Martingale methods simplify the calculation of prices of bonds with embedded options. Duffie and Singleton (1999: 699) relied on the Martingale approach to price option-embedded, defaultable bonds assuming that the issuer calls the bond so as to minimise its market value, which is optimal assuming perfect capital markets and the absence of other motives to exercise bond calls or to postpone exercise. Acharya and Carpenter (2002: 1371) model call options and the possibility of default as American options written on a non-callable, default-free bond with fixed continuous coupons. In a related paper, Guntay (2002: 5) proposes a doublehazard framework to price callable, defaultable coupon bonds. He models call risk and default risk as two correlated hazard processes, while allowing taxes and refunding costs to affect the arrival rate of the call, and firm characteristics to influence the arrival of de-fault. Peterson and Stapleton (2003) address the pricing of options on credit sensitive bonds and build a threefactor model for term structures of default-free yields and for correlated credit spreads. They 
price Bermudan-style options on defaultable bonds using a recombining log-binomial tree methodology.

Kraftb and Munkc (2006) compared the durations of corporate (risky) and Treasury (riskless) bonds in the reduced-form, intensitybased credit risk framework. Using an intensitybased model for corporate bond valuation they found the duration of corporate coupon bonds was larger than the duration of similar Treasury bonds.

Reisz and Perlich (2006: 741) designed novel proxies for the temporal resolution of cash flow uncertainty and found that the later the uncertainty facing the firm is resolved, the larger the yields on corporate debt issued. This in turn affects the estimated Macaulay duration. Reisz and Perlich's data is gleaned only from 1987 and 1996.

Bierwag (1987: 329) considered the problems of defaultability and embedded-optionality from the point of view of simple discounted cash flow pricing models. Using the definition of the Macaulay duration as a price elasticity, he considered the evolution of the Macaulay duration in terms of its constituent factors. $\mathrm{He}$ argued that different cash flows arise from different contingencies and thus give rise to different Macaulay durations. For defaultable securities, the Macaulay duration changes because of different possible cash flow outcomes.
These cash flows are determined from assigned probabilities using hazard rates derived from corporate bond spreads. In the case of optionembedded securities, the Macaulay duration is altered because the probability of exercising the option increases with decreasing yields. In both cases, possible durations may be simulated using bond and bond-option pricing theory. Using Bierwag's ideas, both of the above approaches were explored. The next section explores the effect of default on the Macaulay duration.

\section{3}

\section{Defaultability}

A defaultable bond may be valued using a contingent claims model (Schönbucher, 2003). Within this simple framework, the default time is assumed to be a deterministic variable. The bond is assumed to default only on coupon payment dates. At each coupon date, two possibilities arise: default or survival. In the event of default, the issuer pays only a fraction ${ }^{4}$ of the nominal bond value to the purchaser - no coupon payment is made. If the bond survives, the promised cash flow comprising the coupon payment is paid in the usual manner. This situation is shown below in Figure 1 for a bond with three coupon payments, and with symbols defined below.

Figure 1

Cash flows associated with a risky (defaultable) bond

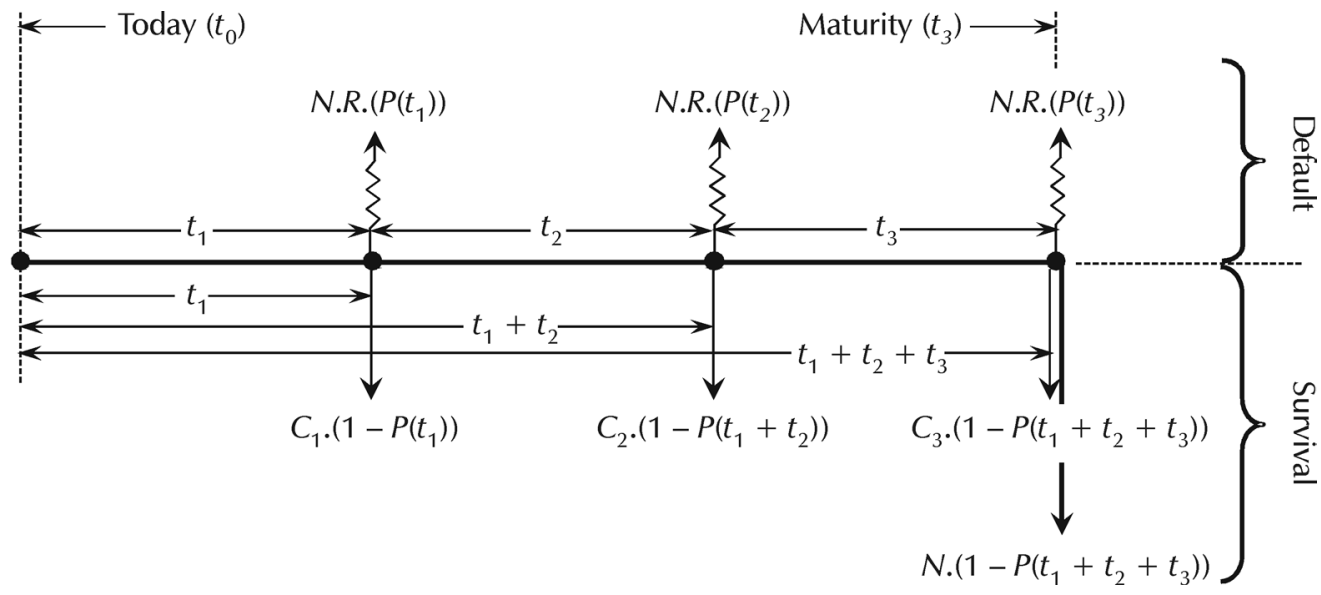

Source: Schönbucher, 2003. 
The equation governing the price of such a bond is:

$$
P\left(t_{0}\right)=\sum_{j=1}^{n} N \cdot R \cdot\left(P_{\mathrm{M}}\left(t_{j}\right)\right) \cdot e^{-r t_{j}}+\sum_{i=1}^{n} c_{i} \cdot\left(1-P_{\mathrm{A}}\left(t_{i}\right)\right) \cdot e^{-r t_{i}}+N \cdot e^{-\mathrm{rt}_{\mathrm{n}}} \cdot\left(1-P_{\mathrm{A}}\left(t_{n}\right)\right)
$$

where

$$
\begin{array}{ll}
P\left(t_{0}\right) & \text { is the price of a defaultable bond at time } t_{0}, \\
N & \text { is the face value of the bond, } \\
R & \text { is the recovery rate, expressed as a percentage, } \\
P_{\mathrm{M}}\left(t_{j}\right) & \text { is the marginal probability of default in the period } j-1 \text { to } j \\
r & \text { is the relevant discount rate, } \\
e^{-n_{i}} & \text { is the continuously compounded discount factor for the } i^{\text {th }} \text { period, } \\
t_{j} & \text { is the } j^{\text {th }} \text { coupon period, } \\
c_{i} & \text { is the } i^{\text {th }} \text { coupon cash flow, } \\
P_{\mathrm{A}}\left(t_{i}\right) & \text { is the cumulative, absolute probability of default since } t_{0}, \\
n & \text { is the number of payment periods until maturity (Schönbucher, 2003). }
\end{array}
$$

Thus, for example, a risky (i.e. defaultable) 18-month, semi-annual coupon bond (three payment dates) is valued by discounting the cash flows indicated in Figure 1, by the continuously compounded yield to maturity, $r$.

Bierwag (1987: 325) acknowledges that calculating the Macaulay duration for the defaultable bond illustrated above, but ignoring the possibility of default, may be severely inaccurate. The promised cash flows may not materialise because of default losses and thus, neither may the yield to maturity. Bierwag asserted that, if $F_{t}$ is the promised cash flow at time $t$, it may be replaced by an expected cash flow, $F_{t}^{*}$ which adjusts in some way for default losses. Assuming no other risks, the expected default losses may be accounted for using the risk free rate of return, $r_{F}$. The actual yield to maturity, $r\left(>r_{F}\right)$, includes the risk premium. Discounting the adjusted flows at the adjusted rate should be equivalent to discounting the promised flows at the risk free rate. If $P\left(t_{0}\right)$ is the price of such a security at $t_{0}$, then it may be valued both as the sum of $n$ risky cash flows discounted at the risk free rate or the sum of risk-free cash flows discounted at the risky rate:

$$
P\left(t_{0}\right)=\sum_{t=1}^{n} F_{t}^{*} \cdot e^{-r_{F} t}=\sum_{t=1}^{n} F_{t} \cdot e^{-r t}
$$

Two durations may thus also be calculated: one using $F_{t}^{*}$ and $r_{F}$ and the other using $F_{t}$ and $r$.
There is no reason to expect the two durations to be equivalent.

Note that Equation 1 may be used to price both risky and riskless bonds. In the latter case, $P_{A}(i)$ is set to 0 for all $i$ and the first term on the right hand side is ignored. This is then the standard discounted cash flow approach to measuring the price of a bond.

Estimating empirical probabilities of default in order to determine the price of a risky bond (Equation 1) is possible, but non-trivial. Li (1998: 42) used a hybrid approach of some of the credit models described in Section 2. The approach estimates hazard rates from observed credit spreads from which default probabilities are derived.

The credit curve is as central to the pricing of credit derivatives and defaultable securities as the yield curve is to fixed income instruments. A credit curve gives the instantaneous probability of default of a party at any time in the future. $\mathrm{Li}$ (1998: 42) proposed a hybrid of the reduced-form and intensity-based models described above for the construction of a credit curve, based entirely on market-observable data. Yields to maturity of corporate securities may be obtained from market prices and these may be compared with the yields to maturity of treasury (i.e. riskless) securities. A spread curve is thus obtained. An exogenous assumption about the recovery rates for these securities is made using the seniority 
and rating of these securities coupled with knowledge of the industrial sector to which the issuing corporation belongs (Houweling \& Vorst, 2001).

Li's (1998) approach differs from rating agencies such as Moody's Investor Service (Dwyer \& Stein, 2004: 798) or Standard and Poors, in that market information - rather than historical information - is used at all times. $\mathrm{Li}$ justified his approach by recognising that not only do rating agencies react more slowly than the market, to changes in future credit quality of corporate securities, but the information they provide is primarily used to estimate default frequency rather than default severity. Credit derivative values depend on both these parameters. In addition, rating agencies usually provide the one year default probability and the rating migration index for each rating group. Neither of these is necessarily stable over long periods. Many corporate securities and credit derivatives have maturities beyond one year, necessitating the use of long term marginal default probabilities (Caouette et al., 1998: 88, Houweling \& Vorst, 2001). Finally, a trading book's profit and loss (P\&L) - has this term appeared before in full? can only be based on current market information since it is that information that reflects the market-agreed perception about the evolution of movements in the market in the future (Rutkowski \& Bielecki, 2003: 18). Current default rates may differ considerably from historical default rates (Cantor \& Falkenstein, 2001: 47).

Using only market information also has associated setbacks. Only a few large corporates have a series of outstanding debts with the same seniority and multiple maturities (both required as inputs for Li's model). However, in the absence of this information, asset swap spreads from similar firms may be used as a proxy.

The advantages of using hazard rates to drive the regular geometric distribution approach are that they are simpler to apply in practice, they combine well with fixed income mathematics and they may be consistently applied to each period. Hazard rates translate directly into default probabilities and are extensively used in Li's (1998) model. A new methodology introduced by $\mathrm{Li}^{5}$ (1998: 41) makes direct use of observed market credit spreads to determine hazard rates and hence default probabilities. It was this model that was employed in the testing of South African data.

The assumptions made by Li's (1998) model are:

1. when default occurs, the bond holder receives a fixed percentage of the bond price (i.e., the recovery rate) immediately prior to default (see Duffie \& Singleton, 1999: 693 for a similar argument),

2. the credit curve consists of a series of default probabilities over each period, conditional to the survival from the beginning of the period (conditional marginal Martingale default probabilities),

3. the current time is used as the time origin to allow use of current market information to build credit curves and

4. the meaning of 'default' is the same as that defined by a number of rating agencies, such as Moody's in Dwyer et al. (2004: 800).

Li's starting point is the Duffie and Singleton (1999: 701) model for pricing defaultable fixed income securities, given by:

$$
P\left(t_{0}\right)=\sum_{i=1}^{n} D F\left(t_{0}, t_{i}\right) \cdot\left(\prod_{j=0}^{i-1}\left[p_{j}+\left(1-p_{j}\right) \cdot R\left(t_{i+1}\right)\right]\right) \cdot c_{i}
$$

where
$P\left(t_{0}\right) \quad$ is the defaultable bond price measured at $t_{0}$,
$D F\left(t_{0}, t_{i}\right)$, the discount factor, is measured at $t_{0}$ for a time $t_{i}$,
$p_{i}$, the conditional survival probability is measured over the period $t_{i}$ to $t_{i+1}$,
$R\left(t_{i+1}\right), \quad$ the recovery rate measured over the period $t_{i}$ to $t_{i+1}$ and
$c_{i} \quad$ is the $i^{\text {th }}$ cash flow, occurring at $t_{i}$. 
Equation 3 above is also referred to as the discrete model in which default is assumed to occur only at the end of the default period.
The continuous model of default, which allows for default at any stage in the period under consideration, is given by:

$p_{n}=P($ surviving period $n t)=e^{-\int_{t_{n}}^{t_{n+1}} h(s) d s}$.

Expanding the square brackets in Equation 3 and making use of Equation 4 gives (if $\Delta t=t_{i+1}-t_{i}$ is small):

$p_{n}+\left(1-p_{n}\right) \cdot R\left(t_{i+1}\right)=e^{-\int_{t_{n}}^{t_{n}} h(s) d s}+\left(1-e^{\left.-\int_{t_{n}}^{t_{n+1}} h(s) d s\right)} \cdot R\left(t_{n+1}\right) \approx e^{-\left(1-R\left(t_{n+1}\right)\right) \cdot \int_{t_{n}}^{t_{n+1}} h(s) d s}\right.$

The credit discount factor (large round brackets

in Equation 3) is:

$\prod_{n=0}^{i-1}\left[p_{n}+\left(1-p_{n}\right) \cdot R\left(t_{i+1}\right)\right] \approx \prod_{n=0}^{i-1} e^{-\left(1-R\left(t_{n+1}\right)\right) \cdot \int_{t_{n}}^{t_{n+1}} h(s) d s} \approx e^{i=\sum_{n=0}^{-1} \int_{t_{n}}^{t_{n+1}}\left(1-R\left(t_{i+1}\right)\right) \cdot h(s) d s}$

Dividing the time interval $\left(o, t_{i}\right)$ into many smaller time intervals of length $\Delta t=t_{i} / n$, and allowing $\mathrm{n} \rightarrow \infty$ allows Equation 3, the discrete

$P\left(t_{0}\right)=\sum_{i=1}^{n} c_{i} \cdot e^{-\int_{0}^{t_{i}}[r(s)+(1-R(s)) \cdot h(s)] d s}$,

where the symbols have the same definitions as Equation 3 and $D F\left(t_{0}, t_{i}\right)=e \int_{0}^{t_{i}} r(s) d s$, where $r(s)$ is the short rate.

Thus armed, empirical data may now be used to price a risky (defaultable) bond using empirical credit spreads, using Equation 1 and 5. South African market data were used for all inputs. ${ }^{6}$ A sample of 120 option-free, corporate bonds was selected spanning the 10 -year period from January 1997 to December 2006. Bond maturities ranged from $0.5 \leq t \leq 30$ years and were of varying credit quality, ${ }^{7}$ from AAA (investment grade) to CCC (highly speculative ${ }^{8}$ grade). Credit spreads over the South African yield curve were obtained from Bloomberg ${ }^{\mathrm{TM}}$, stated either as a fixed, parallel spread (single value over all maturities) or as a term structure (different for all maturities). ${ }^{9}$ Option-free bonds with long dated maturities ( $t>25$ years) are virtually non-existent. As the period selected approaches the present (2007), option-free model, to be reformulated into the continuous model, namely: corporate bonds with shorter maturities become increasingly difficult to source, reflecting both issuer and purchaser reluctance to lock in interest rates for even short periods. Coupons ranged between 8 per cent and 16 per cent and were paid with varying frequency (quarterly, semi-annually or annually). Recovery rates used were those associated directly with the issuer (as reported by corporate news services, such as Reuters $^{\mathrm{TM}}$ and Bloomberg $\left.{ }^{\mathrm{TM}}\right)$. Where data were particularly limited a recovery rate of 40 per cent was used, this being the average recovery rate for South African corporate bonds over the period under examination (Moody's, 2005).

Figure 2a through c shows the relevant averaged parameters obtained for the sample of defaultable corporate bonds measured over the observation period. 


\section{Figure 2}

(a) Conditional hazard rates, (b) cumulative hazard rates and (c) credit spreads for 120 South African corporate (defaultable) bonds over the period January 1997 to December 2006
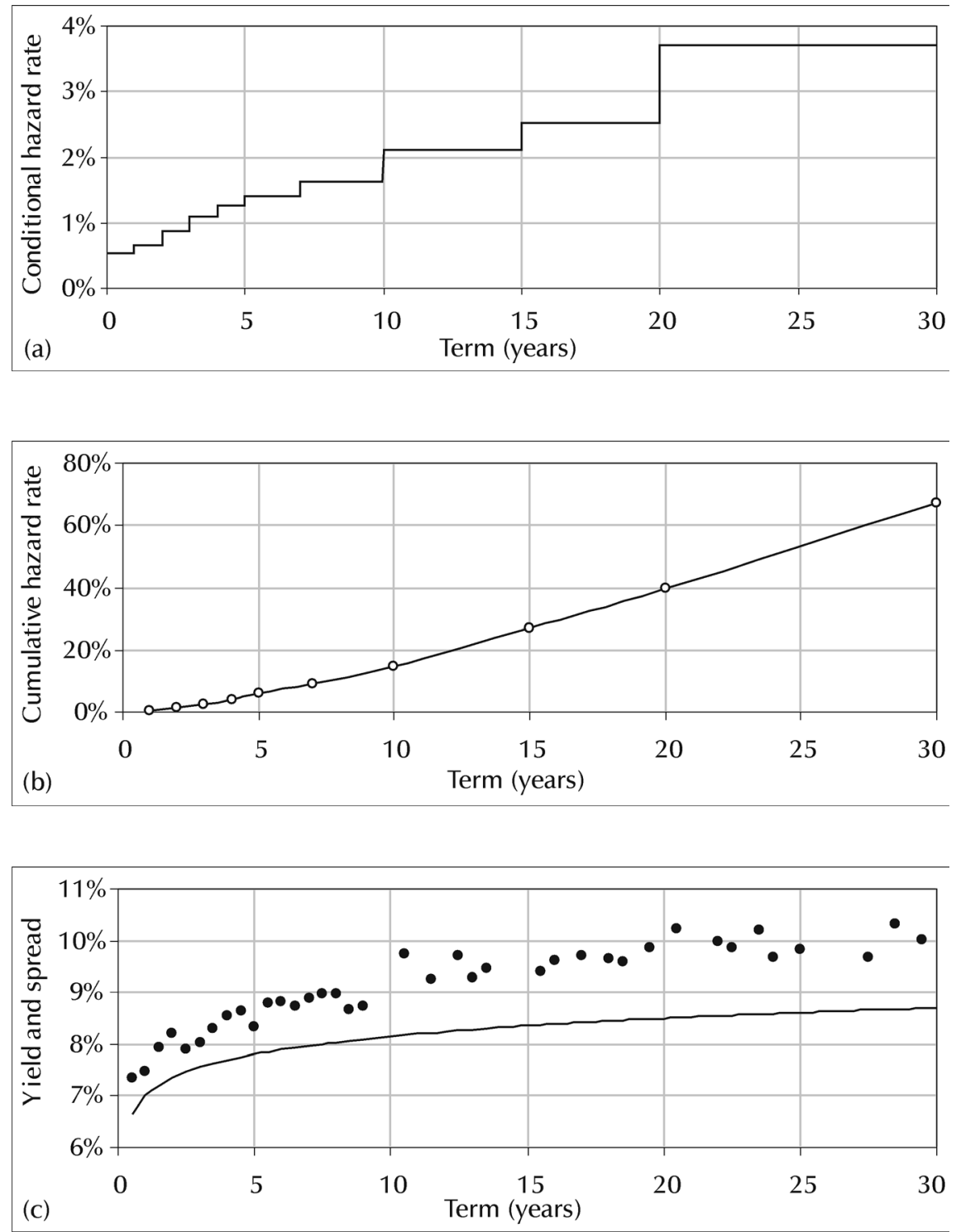

The results shown in Figure 2 may be used as input into Equation 5 and the Macaulay durations ${ }^{10}$ of both defaultable and default-free bonds may thus be measured. Figure 3 shows the Macaulay duration assuming no default and the Macaulay duration assuming the possibility of default for a long-dated corporate bond (maturity $=30 \mathrm{y})$. For low yields, the defaultable bond duration is approximately that of the default-free bond, whilst at increasing yields, the defaultable duration is consistently higher (at high yields, by as much as 100 per cent) than that of the default-free bond for all yields, as shown in Figure 3. 


\section{Figure 3}

Theoretical duration/yield relationship for a $30 y$ defaultable and default-free bond

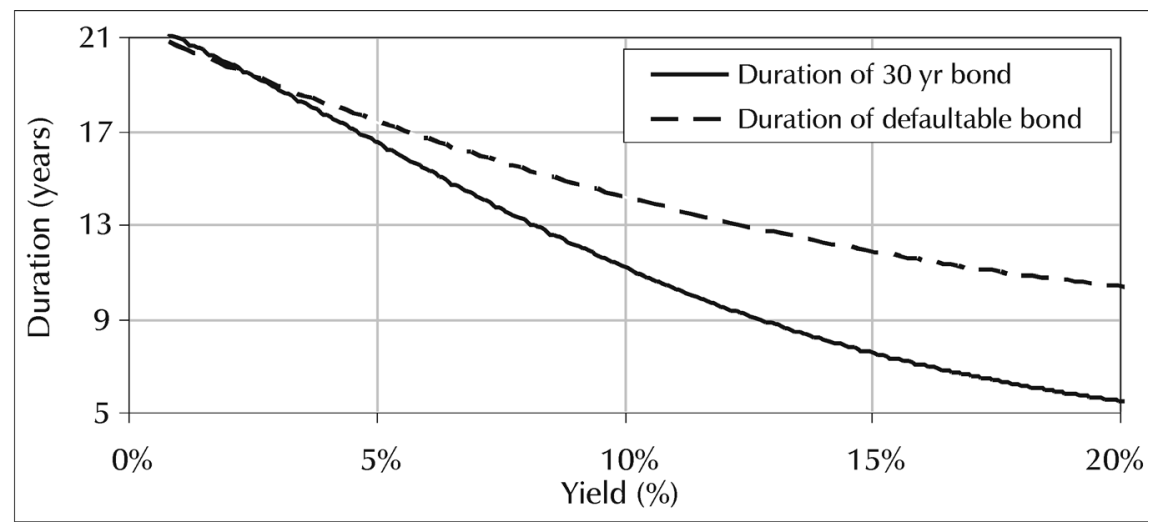

A comparison may now be made between empirically-observed, defaultable bond price changes and those bond price changes predicted using Equation 5 (i.e. for defaultable and default-free Macaulay durations with various changes in yield). To make a sample-for-sample comparison, predicted bond price changes were regressed on actual (empirical) bond price changes. The results are shown in Figure 4 below. Blank circles represent bond price changes as forecast by the default-free Macaulay duration for the 120 bonds in the sample. Filled circles are bond price changes predicted by the default-prone Macaulay duration (combining Equations 2 and 5).

Figure 4

Regression of estimated bond price changes on empirically-observed bond price changes

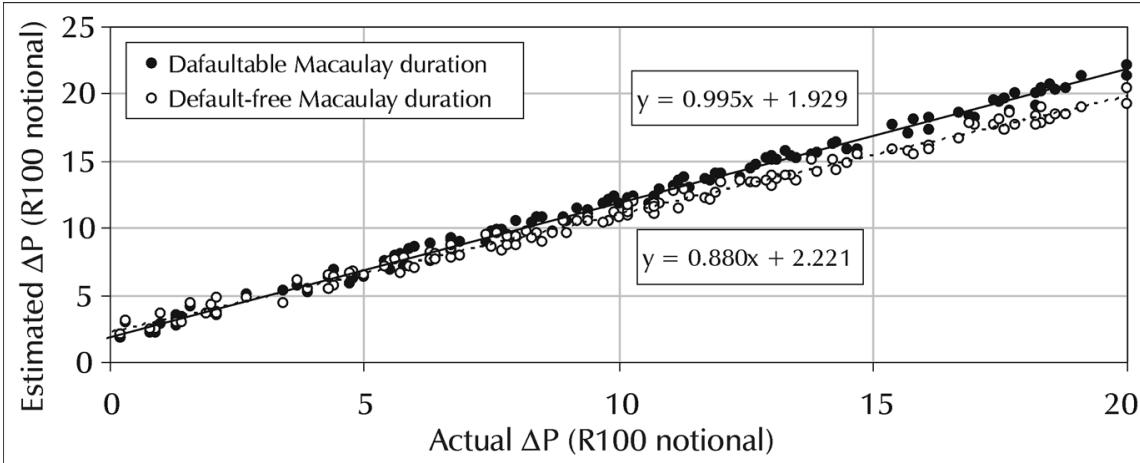

Regression results are shown in Table 1 below. A gradient of 1.00 indicates a perfect fit with observed bond price changes. The defaultprone Macaulay duration gradient is 1.00 within confidence intervals of both 95 per cent and 99 per cent, whilst the default-free Macaulay duration gradient is not 1.00 at either significance level. 


\section{Table 1}

Regression statistics for default-free and defaultable Macaulay-duration bond price change forecasts

\begin{tabular}{|l|c|c|c|c|}
\hline \multicolumn{1}{|c|}{ Regression statistics } & Default-free Macaulay duration & \multicolumn{2}{c|}{ Defaultable Macaulay duration } \\
\hline Multiple R & \multicolumn{2}{|c|}{0.996} & \multicolumn{2}{c|}{0.997} \\
\hline $\mathrm{R}^{2}$ & \multicolumn{2}{|c|}{0.992} & \multicolumn{2}{c|}{0.431} \\
\hline Standard error & \multicolumn{2}{|c|}{0.428} & Intercept & Gradient \\
\hline Observations & \multicolumn{2}{|c|}{120} & 1.929 & 0.995 \\
\hline & Intercept & 0.880 & 23.606 & 134.402 \\
\hline Coefficients & 2.221 & 119.762 & 1.767 & 0.980 \\
\hline$t$-statistic & 27.373 & 0.865 & 2.091 & 1.009 \\
\hline Lower 95\% & 2.061 & 0.895 & 1.715 & 0.975 \\
\hline Upper 95\% & 2.382 & 0.861 & 2.143 & 1.014 \\
\hline Lower 99\% & 2.009 & 0.899 & & Source: Authors, 2007 \\
\hline Upper 99\% & 2.434 & & & \\
\hline
\end{tabular}

These results are consistent with FRS (1997), Nawalkha (1999) and Xie (2002), but contradict those of Fons (1990), BMP (1997) and Acharya et al. (2002: 1382). More work needs to be done to incorporate the combined effects of embedded-optionality and defaultability - or to better separate their effects - before a definite conclusion may be drawn.

Having examined the consequences of corporate bond defaultability on the Macaulay duration, the next section reviews and extends the probability of exercising an embedded option on the Macaulay duration of corporate securities.

\section{4}

\section{Embedded optionality}

A common feature of contemporary corporate bonds is embedded optionality. Such bonds comprise a standard, option-free bond as well as a call or put option on the bond such that, in the case of a callable corporate bond, the issuer may redeem the bond at a pre-specified price (usually par). In addition, the call option may only be exercised after the bond has been outstanding for a pre-specified number of years. ${ }^{11}$ Given the standard inverse law governing bond prices and yields, the callable bond's strike price will have an associated 'call strike' yield, $r^{*}$. Such a bond's price volatility behaves differently from an option-free bond: price movements are relatively constrained, for example, when the price is near the strike. The bond price also exhibits negative convexity when interest rates fall below the yield strike. The durations of option-embedded and option-free bonds then, must also be different.

Bierwag (1987: 326) approached the problem of callable ${ }^{12}$ bond duration from the perspective of a 'shift' in the Macaulay duration near $r$ *. Assuming a callable bond with underlying bond maturity $m$ and earliest call exercise date $n$, Bierwag asserted that such a bond's price and duration would behave like those of a noncallable bond of maturity $m$ if current interest rates, $r$, were much higher than the strike yield i.e. $r>r^{*}$ (and it is obvious the bond would not be called). The bond's price and duration would behave like those of a non-callable bond of maturity $n$ if current interest rates were much lower than the strike yield, i.e. $r<r^{*}$ and it is certain that the call option would be exercised. When interest rates were near the strike yield, 
the bond's price and duration would behave as those of a bond with intermediate maturity (i.e. between $n$ and $m$ ). Bierwag - focussing specifically on duration - argued that the duration 'drift' would not be abrupt, i.e. there would be a gradual change in duration from that of a bond with maturity $n$ to that with maturity $m$ as interest rates increased. Bierwag did not, however, expand his analysis beyond these simple intuitive observations and did not provide a mathematical description of this drift.

Using Bierwag's suggestions as a starting point, bond option pricing and probability theory were combined to extend and quantify his ideas. The aim is to establish a description of the Macaulay duration of a callable bond with maturity $m$ and time to first call $n$. To accomplish this aim, the callable bond must be priced at given times for all yields. It is well known that the callable bond price is simply the difference in price between that of the call-free bond and the call option itself, namely:

$P_{\text {callable }}=P_{\text {call-free }}-c$,

where $c$ is the call option price.

Black's (1995) equation for the price of a call option on a bond was used, namely

$c=P(0, T) \cdot\left[F_{0} \cdot N\left(d_{1}\right)-K \cdot N\left(d_{2}\right)\right]$

where

$c$ is the call option price,

$P(0, T)$ is the price of a zero coupon bond paying 1 at time $T$ and measured at $t=0$,

$F_{0}$ is the forward price of the bond, measured at $t=0$,

$K$ is the call strike price,

$d_{1}=\frac{\ln \left(\frac{F_{0}}{K}\right)-\frac{\sigma^{2} \cdot T}{2}}{\sigma \cdot \sqrt{T}}$,

$d_{2}=d_{1}-\sigma \cdot \sqrt{T}$,

$\sigma$ is the bond's forward price volatility,

$N(\ldots)$ is the cumulative probability density of the quantity in parenthesis and $N\left(d_{2}\right)$ is the probability of exercising the call option.
The price of a call-free bond, $P_{\text {call-free }}$, may be estimated using standard bond pricing techniques and the call option price, $c$, is determined using Equation 7. The callable bond price, $P_{\text {callable }}$ (Equation 6) may thus be easily calculated. These quantities are essential to test Bierwag's assertion: the durations of the respective bonds cannot be determined without them. Establishing the way in which these respective durations are connected is, however, a crucial step which must be taken if any progress is to be made. Note that the callable bond will either be called (with probability $N\left(d_{2}\right)$ ) or not (with corresponding probability $1-N\left(d_{2}\right)$ ). The assertion is thus made that the duration of the callable bond is a simple linear combination of probabilities:

$$
\begin{aligned}
D(t, m, n)_{\text {callable }}= & D(t, m)_{\text {call-free }}\left[1-N\left(d_{2}\right)\right]+ \\
& D(t, n)_{\text {call }}\left[N\left(d_{2}\right)\right]
\end{aligned}
$$

where

$D(t, m, n)_{\text {callable }}$ describes the duration of the callable bond, measured at time $t$, with underlying bond maturity of $m$ years and time to first call of the embedded option of $n$ years,

$D(t, m)_{\text {call-free }}$ is the duration of the underlying, option-free bond ( $m$ in Bierwag's formulation) measured at time $t$ and

$D(t, n)_{\text {call }}$ is the duration of a bond with maturity equal to the earliest call date ( $n$ in Bierwag's formulation), measured at time $t$.

When interest rates are much lower than the strike rate, $r^{*}$, i.e. $r<r^{*}$, the probability of exercising the call option is high $\left(N\left(d_{2}\right) \cong 1\right)$, the first term on the right hand side of Equation 8 becomes negligible and the callable bond duration becomes $D_{\text {callable }} \cong D_{\text {call }}$. On the other hand, if interest rates are much higher than the strike rate, i.e. $r>r^{*}$, the probability of exercising the call option is low $\left(N\left(d_{2}\right) \cong 0\right)$, the second term on the right hand side of Equation 8 becomes negligible and the callable bond duration shifts to that of the call-free bond, i.e. $D_{\text {callable }} \cong D_{\text {call-free }}$. In between, i.e. where $r \cong r^{*}$, Equation 8 applies. 
Corporate bonds with embedded call options are common in the South African fixed income market. Whilst the time to first call varies considerably from callable bond to callable bond (whose maturities vary from 8 to 20 years), those callable bonds with a first call time of five years (by far the most popular time span) were chosen a provide the greatest amount of data. Bonds with maturities of $8,10,12$ and 15 years - each with embedded callable options with time to first call of 5 years - were thus selected and Equation 8 applied. The Macaulay duration of each of the callable bonds was calculated for a range of interest rates at inception $(t=0)$. Figures 5(a) through (d) below display results for bonds with maturities and time to first call options as indicated on the graphs. Note that "call adjusted duration" lines are outputs from the application of Equation 8 to the relevant bonds, i.e. $D(0, m, n)_{\text {callable }}$ where $8 \leq m \leq 15$ years and $n=5$ years. The scaling of both $x$ - and $y$-axes are the same for comparison.

It is clear from Figure 5 that all of Bierwag's assertions are satisfied. At yields much lower than the strike yield $\left(r<r^{*}\right)$ the duration is that of a bond with the same maturity as the time to first call. At yields much higher than the strike yield $\left(r>r^{*}\right)$ the duration is that of the option-free bond. In between, the callable bond's duration is bounded by these two possible durations and changes gradually near $r=r^{*}$.

Figure 5

Durations of (a) 8y bonds, (b) 10y bonds, (c) $12 y$ bonds and (d) $15 y$ bonds all with embedded call options with time to first call of $5 y$

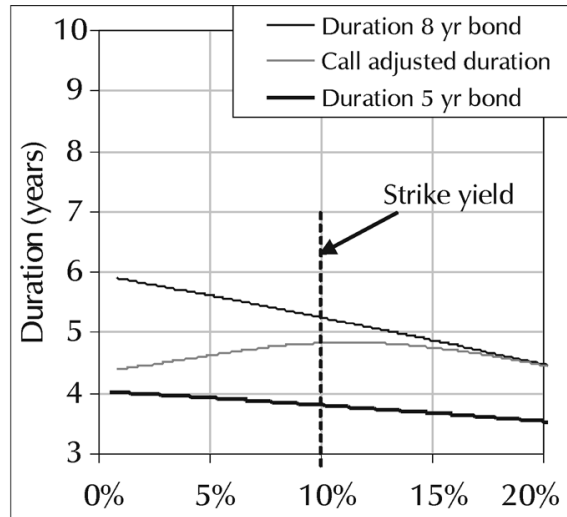

(a) $8 y$ bonds, $5 y$ call options Yield (\%)

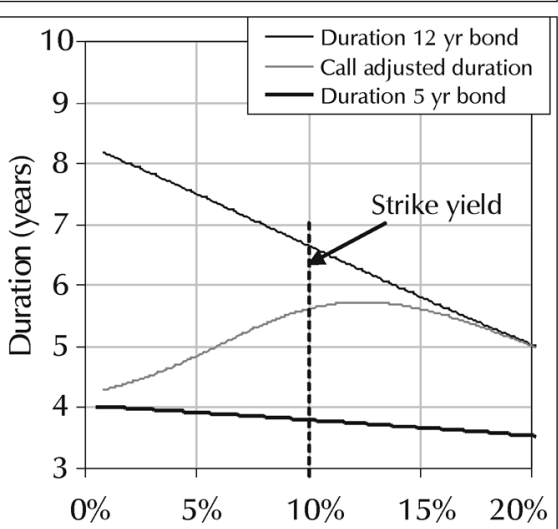

(c) $12 y$ bonds, $5 y$ call options Yield (\%)

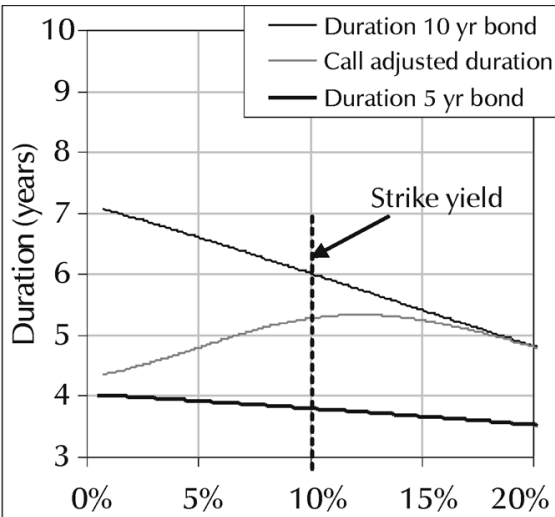

(b) $10 y$ bonds, 5 y call options Yield (\%)

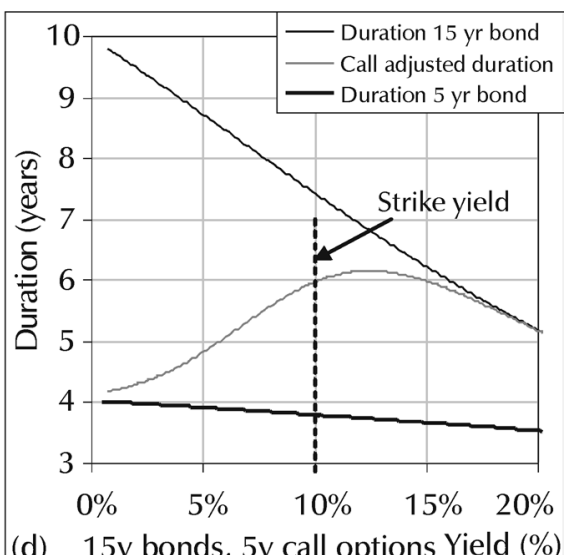


To determine the evolution in time of the changing duration curve given by Equation 8 (i.e. to establish $D(t, m, n)_{\text {callable }}$ over $\left.t \in(0, n)\right)$, the duration of bonds with maturity equal to time to first call and the underlying bond were evaluated at 6 month intervals from $t=0$ until the option expiry date ( $t=5$ years) using Equation 8. After 6 months, the callable bond in Figure 5(a), for example, comprises an option-free bond with 7.5 years to maturity and a call option with 4.5 years until first callable date. After 2 years, the option-free bond has 6 years to maturity and the call option has only 3 years until the first callable date, and so on. This time-changing profile is shown in Figure 6, below.

\section{Figure 6}

Evolution in time of the callable bond duration range described in the text

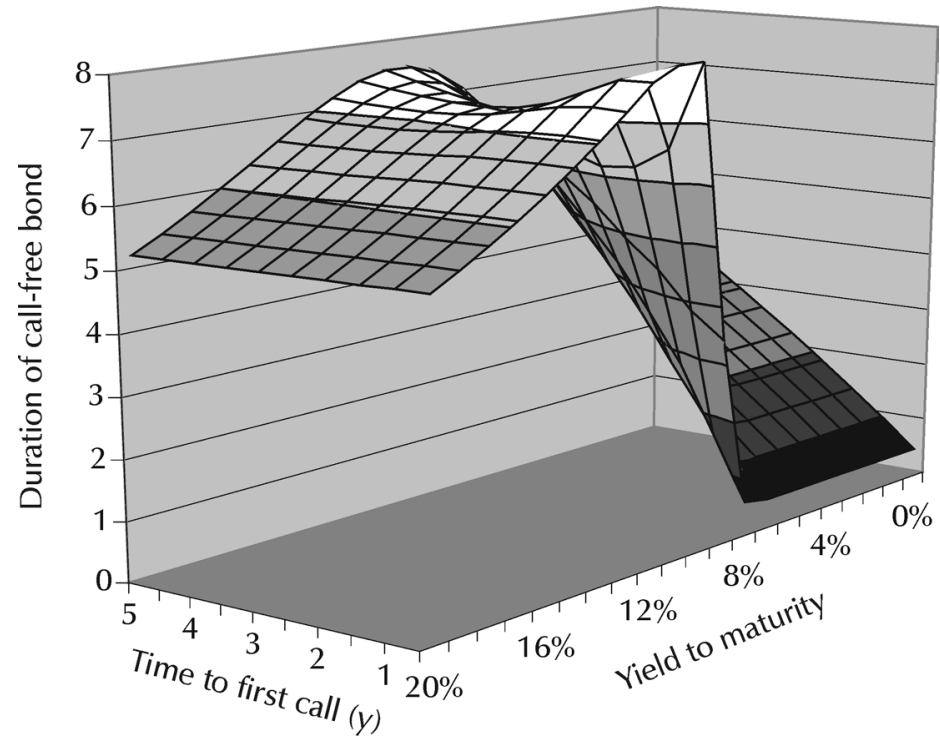

Source: Bloomberg ${ }^{\mathrm{TM}}, 2007$

The standard elasticity definition of duration is

$\frac{\Delta P}{P} \cong-D \cdot \Delta r$,

where

$\frac{\Delta P}{P}$ is the relative price change in percent,

$D$ is the modified duration and $\Delta r$ is the yield change.

Bierwag (1987: 328) pointed out that, using Equation 9, large decreases in interest rates should result in large price increases. However, if the duration also decreases as interest rates fall (see Figure 5), the accompanying increase in price will not be as large. Bierwag noted that in the period from January to May 1986 - when interest rates dropped precipitously - many callable bonds experienced precisely such a lacklustre increase in prices despite the large drops in interest rates. As interest rates dropped to levels near to but still above $r^{*}$, the duration also decreased. The percentage increase in bond prices represented insufficient increments to bond portfolio values to offset the reduced future earnings from reinvesting at lower rates. Previously high yields could not be locked in over long planning periods and durations of bond portfolios were too short to immunise over such planning periods. The realised rates of return over such planning periods are thus likely to be significantly less than many investment managers had projected for their clients. Similarly, significant, rapid interest rate decreases have also been experienced in the South African interest rate market in recent years (see Figure 7). A 45 per cent decrease in interest rates (600 basis points, from 13 per cent to 7 per cent) was observed over a period of one year 
(2003). Bond portfolio values did increase over this period, but not as significantly as predicted by standard duration analysis (van Veen, 2006). Since these portfolios comprise many corporate callable bonds of varying first-to-call dates, it is possible that Bierwag's duration drift effect is partially responsible for these unimpressive portfolio value increases.

Figure 7

Daily 3m South African interest rates since January 2002.

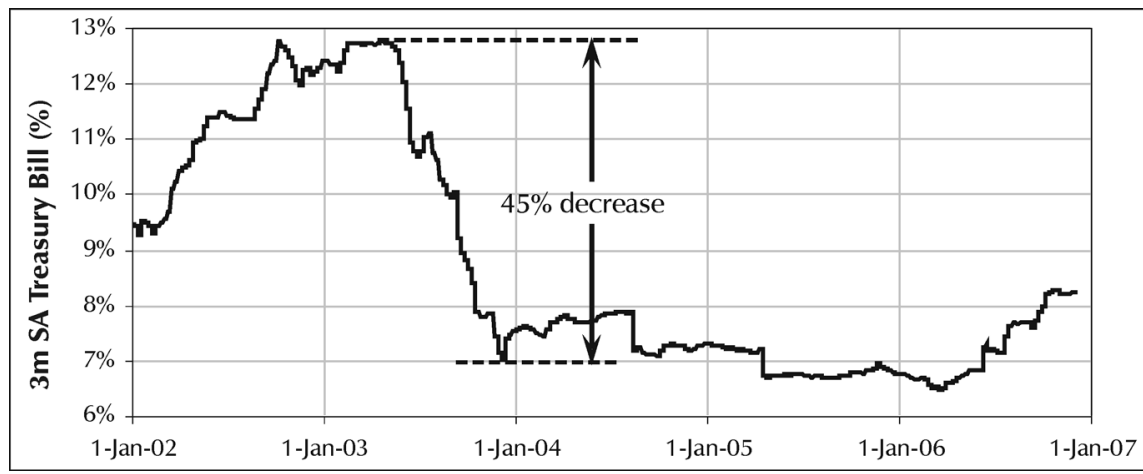

Source: Bloomberg ${ }^{\mathrm{TM}}, 2007$

In order to test this possibility, actual percentage bond price changes for several callable bonds ${ }^{13}$ were plotted against corresponding changes in interest rates, both positive and negative. Using Equation 9 (and ignoring the small effect of convexity), the relationship between these two quantities is constant and equal to $-D$. Equation 8 , however, predicts a duration which 'drifts' as $\Delta r$ changes - smoothly changing from the duration of the underlying option-free bond to that of a bond with a maturity equal to the first callable date of the embedded option. The results are shown in Figure 8 below. In each case, Equation 8 is a more accurate forecaster than Equation 9, as shown by the regression statistics in Table 2.

\section{Figure 8}

$\frac{\Delta P}{P}$ versus $\Delta r$ for samples of bonds having the same characteristics as those in the corresponding figures $5(\mathrm{a})$ through $(\mathrm{d})$
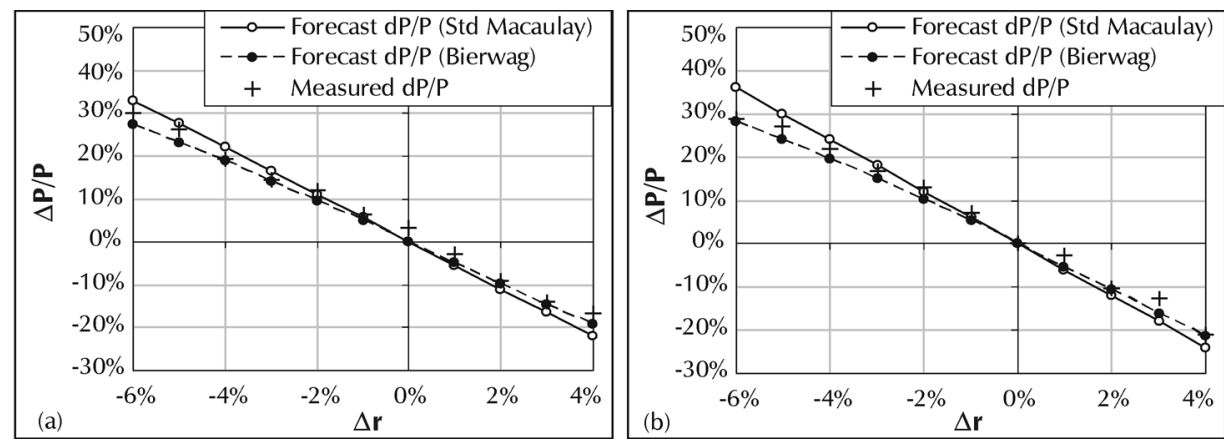

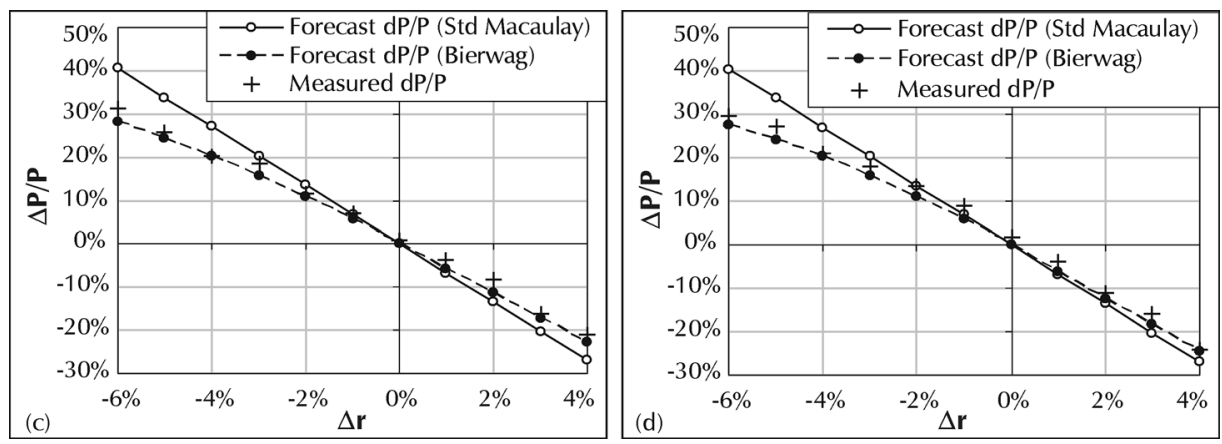

Table 2

Regression statistics for price changes forecast by (a) standard Macaulay analysis and (b) the duration drift technique on observed relative price changes

\begin{tabular}{|c|c|c|c|c|}
\hline Regression statistics & \multicolumn{2}{|c|}{$\begin{array}{l}\text { (a) Price change forecast by } \\
\text { Equation } 9 \text { (Standard Macaulay) }\end{array}$} & \multicolumn{2}{|c|}{$\begin{array}{l}\text { (b) Price change forecast by } \\
\text { Equation } 8 \text { (Bierwag) }\end{array}$} \\
\hline Multiple R & \multicolumn{2}{|c|}{0.994} & \multicolumn{2}{|c|}{0.999} \\
\hline $\mathrm{R}^{2}$ & \multicolumn{2}{|c|}{0.988} & \multicolumn{2}{|c|}{0.998} \\
\hline Std error & \multicolumn{2}{|c|}{0.026} & \multicolumn{2}{|c|}{0.009} \\
\hline \multirow[t]{2}{*}{ Observations } & \multicolumn{2}{|c|}{110} & \multicolumn{2}{|c|}{110} \\
\hline & Intercept & Gradient & Intercept & Gradient \\
\hline Coefficients & -0.006 & 1.240 & -0.018 & 0.984 \\
\hline$t$-statistic & -0.675 & 27.051 & -6.270 & 62.050 \\
\hline Lower 95\% & -0.024 & 1.136 & -0.024 & 0.948 \\
\hline Upper 95\% & 0.013 & 1.344 & -0.011 & 1.020 \\
\hline Lower 99\% & -0.033 & 1.091 & -0.027 & 0.932 \\
\hline Upper 99\% & 0.021 & 1.389 & -0.009 & 1.036 \\
\hline
\end{tabular}

Source: Authors, 2007

5

\section{Conclusion}

Most prior research has explored the theoretical importance of adjusting Macaulay duration for the dual impacts of defaultability and callability. Simple, robust duration measures have been developed within a new theoretical framework to account for the differences observed between durations of defaultable and default-free, and callable and option-free, bonds. Observed differences between portfolios with and without defaultable or callable bonds are well explained by the new methodology and the results showed consistency with much of the prior research. The duration of defaultable securities is consistently higher than that of corresponding defaultfree bonds and the duration of callable bonds although subject to many variables, is bounded by the duration of the underlying option-free bond and that of a bond with a maturity equal to the first callable date. 


\section{Endnotes}

1 Credit risk arises from the potential of a borrower or counterparty to fail to meet its obligations in accordance with agreed terms.

2 Market risk reflects the possibility that a portfolio will incur economic losses due to changes in prices, interest rates and other market variables.

3 Although operational risk is a completely new addition to the new capital standards introduced by the BIS, it does not play a role in this discussion.

4 As determined by the recovery rate, $R$.

5 This work was later refined by Schönbucher (2003:65).

6 The South African corporate bond market is relatively small compared to those of developed economies (Tikkam, 2005).

7 Fitch ratings. Internal data.

8 Speculative grade corporate bonds, although plentiful in the marketplace, have notoriously high and unreliable credit spreads coupled with low recovery rates. These parameters give rise to highly variable hazard rates and both absolute and cumulative default probabilities. Corporate bonds with speculative grade credit ratings were therefore used sparingly, comprising about 10 per cent of the total sample.

9 In bond contract confirmations from corporates themselves or relevant auditors.

10 The effect of defaultability on the convexity was also examined. The convexity was large for low yields, small for high yields, and of considerably smaller magnitude $\left(<10^{-2}\right)$ than the duration effect. These results add nothing new to the understanding of the effect of defaultability on duration since they are well known from analysis performed on default-free bonds.

11 For example, a 20-year bond may have a call option feature with strike price 100 , exercisable only after 5 years since the inception of the bond or 15 years before ultimate maturity.

12 The analysis that follows involves callable (rather than putable) bonds since the former are far more prevalent and considered a greater risk to investors since the decision to call resides with the issuer - not the owner - of the bond.

13 The bonds chosen were again those selected for the analysis which produced the results shown in Figure 5, i.e. (a) $8 y$ bonds, (b) 10y bonds, (c) $12 y$ bonds and (d) $15 y$ bonds, all with embedded call options with a first to call date of $5 y$.

\section{References}

1 ACHARYA, V.V. \& CARPENTER, J.N. (2002)

"Corporate bonds: Valuation, hedging, and optimal call and default policies", Review of Financial Studies, 15: 1355-83.

2 BABBEL, D.F.; MERRILL, C. \& PANNING, W. (1997) "Default risk and the effective duration of bonds", Financial Analysts Journal, January/ February, : 35-44.

3 BIERWAG, G.O. (1987) Duration Analysis, Ballinger Publishing Company, USA: 324-329.

4 BIERWAG, G.O. \& KAUFMAN, G. (1988)

"Durations of non-default-free securities", Financial Analysts Journal, July/August: 39-46.

5 BIERWAG, G.O.; KAUFMAN, G.G. \& TOEVS, A.T. (1983) "Immunization strategies for funding multiple liabilities", Journal of Financial and Quantitative Analysis, 18: 113-123.

6 BIS Consultative Document (2001) "The standardised approach to credit risk: supporting document to the New Basel Capital Accord", www. bis.org/publ/bcbsca04.pdf (Accessed 4 May 2005)

7 BIS Consultative Document (2005) "Basel II: International convergence of capital measurement and capital standards: A revised framework". http://www.bis.org/publ/bcbs118.htm (Accessed 22 September 2006)

8 CANTOR, R. \& FALKENSTEIN, E. (2001) "Testing for rating consistency in annual default rates", The Journal of Fixed Income, 11, 2: 36-51.

9 CAOUETTE, J.; ALTMAN, E. \& NARAYANAN, P. (1998) Managing Credit Risk: The Next Great Financial Challenge, John Wiley and Sons, New York, 496 pages.

10 CHANCE, D.M. (1990). "Default risk and the duration of zero coupon bonds", Journal of Finance, 35: 265-274.

11 COX, J.C.; INGERSOLL, J.E. JR. \& ROSS, S.A. (1985) "A theory of the term structure of interest rates", Econometrica, 53: 385-408.

12 DUFFIE, D. \& SINGLETON, K.J. (1999)

"Modeling term structures of defaultable bonds", Review of Financial Studies, 12: 687-720.

13 DWYER, D.W. \& STEIN, R.M. (2004) "Inferring the default rate in a population by comparing two incomplete default databases", Journal of Banking \& Finance, 30: 797-810.

14 EOM, Y.H.; HELWEGE, J. \& HUANG, J.J. (2002) "Structural models of corporate bond pricing: an empirical analysis”, EFA, February 2002, Berlin Meetings.

15 FISHER, L. (2004) "Forecasting interest-rate risk over time", http://business.rutgers.edu/departments/ 
fin-papers/04Spring/lfisher.pdf (Accessed 12 October 2006).

16 FONS, J.S. (1990) "Default risk and duration analysis". In: Altman, E.I. (ed.) The High Yield Debt Market, Dow Jones Irwin, New York: 18-40.

17 FOOLADI, I.J.; ROBERTS, G.S. \& SKINNER, F. (1997) "Duration for bonds with default risk", Journal of Banking and Finance, 21: 1-16.

18 GALAI, D. \& MASULIS, R.W. (1976) "The option pricing model and the risk factor of stock", Journal of Financial Economics, November: 115-146.

19 GARMAN, M.B. (1985) "The duration of option portfolios", Journal of Financial Economics, 14, 2: 309-315.

20 GUNTAY, L. (2002) "Pricing the risks of callable defaultable coupon bonds", Working Paper, University of Maryland: 1-18.

21 HEGDE, S.P. \& NUNN, K. (1988) "Noninfinitesimal rate changes and Macaulay duration", Journal of Portfolio Management, Winter 1988: 69-73.

22 HOUWELING, P. \& VORST, A.C.F. (2001) "Pricing default swaps: Empirical evidence", ERIM Report Series Reference No. ERS-2002-23F\&A, http://ssrn.com/abstract $=294799$ (Accessed 5 May 2006).

23 JACOBY, G. (2003) "A duration model for defaultable bonds", Journal of Financial Research, 26, 1: 129-151.

24 JACOBY, G. \& ROBERTS, G.S. (2003) "Defaultand call-adjusted duration for corporate bonds", Journal of Banking \& Finance, 27: 2297-2321.

25 KIHN, J. (1994) "Unravelling the low-grade bond risk/reward puzzle", Financial Analysts Journal, July/August: 32-42.

26 KIM, I.J.; RAMASWAMY, K. \& SUNDAREASAN, S. (1993) "Does the default risk in coupons affect the valuation of corporate bonds?", Financial Management, 22: 117-131.

27 KRAFTB, H. \& MUNKC, C. (2006) "Bond durations: Corporates vs. treasuries”, Department of Mathematics, University of Kaiserslautern and Department of Business and Economics, University of Southern Denmark, November 2006, www.sam.sdu.dk/ cmu/papers/KraftMunk_ duration.pdf (Accessed 17 June 2006).

28 LI, D. (1998) "Constructing a credit curve" (Credit risk special report) Risk Magazine: 40-44.

29 MACAULAY, F.R. (1938) "Some theoretical problems suggested by the movements of interest rates, bond yields, and stock prices in the United States since 1856", Columbia University Press: New York.
30 MERTON, R.C. (1974) "On the pricing of corporate debt: The risk structure of interest rates", Journal of Finance, 29: 449-470.

31 MORGAN, G.E. (1986) "Floating rate securities and immunisation: some further results", Journal of Financial and Quantitative Analysis, 21(1): 87-94.

32 NAWALKHA, S.K. (1996) "A contingent claims analysis of the interest rate risk characteristics of corporate liabilities", Journal of Banking \& Finance, 20: 227-245.

33 NAWALKHA, S.K. (1999) "Duration sixty years later". In: Nawalkha, S., Chambers, D. (Eds.), Interest Rate Risk Measurement and Management, Institutional Investor, New York: 3-17.

34 OTT, R.A. Jr. (1986) “The duration of an adjustable-rate mortgage and the impact of the index", Journal of Finance, 41, 4: 923-934.

35 PETERSON, S. \& STAPLETON, R.C. (2003) "Pricing of options on credit-sensitive bonds", Schmalenbach Business Review, 55, July, http://ssrn. com/abstract $=550702$ (Accessed 3 December 2005).

36 REISZ, A.S. \& PERLICH, C. (2006) “Temporal resolution of uncertainty and corporate debt yields: An empirical investigation", The Journal of Business, 79: 731-770.

37 ROSENBERG, J. (2004) "A general approach to integrated risk management with skewed, fattailed risks". Federal Reserve Bank of New York, Rutgers University Finance Department Seminar. http://business.rutgers.edu/departments/fin-papers/ 04Spring/josh.pdf.

38 RUTKOWSKI, M. \& BIELECKI, T.R. (2003) "Dependent defaults and credit migrations", http:// www.defaultrisk.com/pp_corr_35.htm (Accessed 8 September 2006).

39 SARKAR, S. (2000. "Probability of call and likelihood of the call feature in a corporate bond", Journal of Banking and Finance, 25: 505-533.

40 SCHÖNBUCHER, P. J. (2003) Credit Derivatives Pricing Models, John Wiley: London.

41 VAN VEEN, M. (2006) Private communication.

42 VAN VUUREN, G.W. \& STYGER, P. (2006)

"Duration analysis in South Africa: The search for superior measures", South African Journal of Economics, 74, 2: 266-293.

43 VASICEK, O. (1977) "An equilibrium characterisation of the term structure", Journal of Financial Economics, 5: 177-188.

44 XIE, A.Y.; LIU, S. \& CHUNCHU, W. (2002) "Estimating duration for bonds with default risk", www.cab.latech.edu/public/DEPTS/econ_fin/ papers/xie.htm (Accessed 31 March 2006). 